\title{
Do young schizophrenics with recent onset of illness show evidence of hypofrontality?
}

\author{
O. Gureje, O. Olley, R.A. Acha and B.O. Osuntokun \\ Departments of Psychiatry and Medicine, University College Hospital, PMB 5116, Ibadan, \\ Nigeria
}

Correspondence to: O Gureje, Department of Psychiatry, at above address

\begin{abstract}
Young schizophrenic patients $(n=43)$, manic controls $(n=32)$, both groups diagnosed according to the Research Diagnostic Criteria and on remission from acute illness, and 53 normal subjects were given a battery of neuropsychologic tests selected to assess different functional areas in the brain. Compared with normal controls, patient groups showed evidence of impaired functioning of many cortical areas but with the schizophrenics having the worst performance. In addition, schizophrenic patients performed poorly in tests designed to assess frontotemporal cortical functioning. This pattern of deficits differentiated schizophrenics from both manic and normal subjects. The results suggest that widespread cognitive deficits are a feature of both schizophrenia and mania but that frontal lobe dysfunction may be more specific to the former. It would also appear that these impairments are not artefacts of age, chronicity or of institutionalization, and are present even in schizophrenic patients who may have an illness with putative better outcome than those studied in previous reports.
\end{abstract}

Keywords: Schizophrenia - Neuropsychological assessment - Frontal lobe dysfunction

\section{INTRODUCTION}

The impairments associated with schizophrenia are many and varied (Shakow, 1963; Spitzer et al., 1970; Wallace, 1984; Taylor and Abrams, 1984; Keefe et al., 1987). However, those relating to cognitions are of particular interest to researchers. This is so for a number of reasons. First, cognitive deficits in schizophrenia tend to be persistent and are therefore a frequent source of poor social functioning among patients with the disorder (Gold and Hurt, 1990). Secondly, these impairments, in view of the assumption that they may sometimes predate the clinical manifestation of the disorder (Neale et al., 1984), may serve as pointers to the aetiological origins of the disorder. Thirdly, their differential association with schizophrenia is a useful validation evidence for an illness that is still only poorly delineated from some other psychotic disorders, and can serve as a tool in the on-going attempt to delineate the clinical components of what is increasingly seen as a heterogeneous disorder (Tsuang et al., 1990).

Few people will now argue against the notion that schizophrenia is a brain disease (Mesulam, 1990). However, the demonstration of a differential outcome for the disorder in developed and developing countries (Sartorius et al., 1986), with the implied salience of sociocultural factors in such differences, may suggest that the illness is somewhat less "biological" in the latter countries (Cooper and Sartorius, 1977). The evaluation of neurobiological factors in such societies may thus provide evidence for or against the possibility that the fundamental nature of schizophrenia is different in these two cultural settings.

Neuropsychological tests are useful in the demonstration of the biological substrate of schizophrenia because their validity and putative regional cerebral origins have been established from studies of patients with insults to specific brain areas.

The nature of cognitive deficits in schizophrenia is contentious. Results implicating deficits in specific brain areas include those suggesting involvement of the frontal lobe (Kolb and Whishaw, 1983; Taylor and Abrams, 1984; Weinberger et al., 1986; Goldberg et al., 1987), and of medial temporal and hippocampal systems (Kolb and Whishaw, 1983; Gruzelier et al., 1988; Saykin et al., 1991). Both left and right hemisphere dysfunction have also been reported (Gur, 1978; Gruzelier et al., 1989). While some of these studies would imply that focal cerebral pathology is more characteristic of the disorder, there are other results implicating a diffuse or generalized brain insult in the disorder. Recently, a group of investigators suggested that there may indeed be two 
TABLE I. Demographic features of the subjects (S.D. in parentheses)

\begin{tabular}{lccc}
\hline & $\begin{array}{c}\text { Normals } \\
(n=53)\end{array}$ & $\begin{array}{c}\text { Schizophrenics } \\
(n=43)\end{array}$ & $\begin{array}{c}\text { Manics } \\
(n=32)\end{array}$ \\
\hline Sex (\% female) & 53 & 40 & 56 \\
Age (years) & $27.1(7.78)$ & $29.3(5.59)$ & $27.7(6.73)$ \\
Years of education & $14.6(11.89)$ & $11.9(3.75)$ & $12.7(2.71)$ \\
Social class & $3.6(1.52)$ & $3.2(1.17)$ & $3.1(1.22)$ \\
Age at onset of illness & - & $26.2(5.35)$ & $22.9(5.53)$ \\
$\quad$ (years) & - & $41.2(18.11)$ & $35.7(15.08)$ \\
Length of current & - & & \\
$\quad$ hospitalization (days) & - & $1008.7(526.06)$ & $1270.3(880.15)$ \\
$\quad \begin{array}{lll}\text { Current neuroleptic } \\
\quad \text { dosage }\end{array}$ & - & & \\
$\quad$ (chlorpromazine & & & \\
$\quad$ equivalent, mg) & & & \\
\hline
\end{tabular}

levels of neuropsychological dysfunction in schizophrenia: one generalized and the other involving fronto-temporal cortical systems (Goldberg et al., 1990).

In this report, we examine the nature of neuropsychological impairments in a group of schizophrenic patients with relatively short duration of illness. As this is, to our knowledge, the first such attempt using exclusively black African patients, we have used two groups of controls: normals and manic patients. We were interested in determining whether schizophrenics could be differentiated from the controls using neuropsychological test performance and identifying the pattern of cognitive deficits characteristic of the illness in this sample. We have also examined the relationship between neuropsychological test performance and the constituent syndromes of schizophrenia in order to see whether distinct cognitive profiles could be found for these syndromes.

\section{METHODS}

The study sample consisted of 43 patients with schizophrenia. Controls were 32 patients with mania and 53 "normals". Table I gives demographic details for the subjects. All patients were in-patients on the psychiatric wards of the university teaching hospital at the time of recruitment for the study. Normal controls were junior staff members at the university teaching hospital. All patients fulfilled Research Diagnostic Criteria (RDC; Spitzer et al., 1978) following assessment by a trained assistant with the use of the Composite International Diagnostic Criteria (CIDI; Robins et al., 1988), a structured polydiagnostic interview. Patients were also rated on the Scale for the Assessment of Negative Symptoms (SANS;
Andreasen, 1983) and an abridged version of the Brief Psychiatric Rating Scale (BPRS; Overall and Gorham, 1962). The abridged version of the BPRS consisted of items previously used by other workers to rate positive symptoms: conceptual disorganization, grandiosity, suspiciousness, hallucinatory experience, and unusual thought content. The interview was administered as soon after admission as patients' mental status permitted. The three groups were matched for sex, age and years of education. This was done by ensuring that for every manic patient, there was at least one schizophrenic of same sex and age (within 5 years) and educational level (within 2 years), and that for every schizophrenic, there was at least a normal control of identical features. Thus, because of unequal numbers, two schizophrenics were sometimes matched to a manic while two normals were sometimes matched to a schizophrenic. All the patients were receiving neuroleptic medication at conventional doses at the time of study. While the manics tended to be on a higher level of neuroleptic medication, there was no significant difference between the patient groups in respect of mean neuroleptic dosage, and no significant correlations were found between drug dosage and any of the neuropsychological tests for either of the two groups.

Neuropsychological tests were administered to the patients during the index admission but when active symptoms had remitted. They were carried out by a research clinical psychologist who was blind to the patients' diagnoses but not to the clinical status of the normal subjects. Most subjects completed the tests at a single sitting. All were dextral.

The neuropsychological tests were grouped into five rational content areas: verbal memory, verbal fluency, design fluency, Wechsler Adult Intelligence Scale (WAIS; Wechsler, 1955) performance tests,

60 Behavioural Neurology . Vol 7 . 1994 
and WAIS verbal tests. The verbal memory test was conducted with the use of the Yoruba version of the narrative contained in the Test of the Sensorium (Withers and Hinton, 1971) previously used by the first author (Gureje, 1989). The test is an adaptation of the Logical Memory Test (Wechsler, 1945). Verbal fluency was assessed by the use of two tests. The first was a verbal associative fluency test, modified from the Multilingual Aphasia Examination (Benton and Hamsher, 1976) in which subjects were required to produce as many words as possible beginning with a particular letter in $1 \mathrm{~min}$. Based on data from a pilot study, the letters A and B in the local Yoruba language, the language in which all tests were conducted, were used. The former has many associative possibilities and is therefore easy while the latter has fewer such possibilities and is therefore more difficult. Subjects were instructed to name as many words as possible in $1 \mathrm{~min}$ but to avoid proper nouns and names. The second test of verbal fluency involved the production of as many words as possible belonging to a designated semantic category in $1 \mathrm{~min}$. The category used was animals.

Design fluency was tested by asking the subjects to draw as many designs as possible in 1 min (JonesGotman and Milner, 1977). In the first trial, subjects drew the designs without restriction as to how many lines and curves could be used. In the second trial, subjects were restricted to four lines and curves for each design.

Two tests were administered from the WAIS performance subtests. These were the object assembly and the picture completion subtests. These two were chosen because they are often regarded as the most sensitive and also because they do not contain culture-sensitive items. Two tests were also selected from the WAIS verbal subtests based on similar considerations: digit span and similarities. The similarities subtest was modified in this study by the deletion of three of the 13 items. The deleted items were those for which the Yoruba language lacked adequate concepts for the description of similarities between the pairs in the items. The WAIS tests were administered according to standard specifications.

Three schizophrenics and four manics did not receive the verbal fluency tests. Otherwise, every test was administered to the 53 normals, 43 schizophrenics and 32 manics.

Analysis of variance (ANOVA) was carried out to compare the performance of the three groups on each of the tests. When statistically significant difference $(p<0.05)$ was observed, pairwise comparisons were made with the use of the Tukey HSD statistic to determine the source of the difference. Significance of such comparisons was set at 0.05 .

\section{RESULTS}

Table II shows the means and standard deviations of the scores of the three groups. There was no significant group difference in the performance of the subjects in the immediate recall of the Logical Memory Test. Even though a difference was observed in respect of the delayed recall of the test; with the schizophrenic having the poorest performance, there was however no significant difference between any two of the groups when comparisons were made with the Tukey HSD test.

There was a significant group difference in each of the verbal fluency tests. In the case of the associative test for the letter $\mathrm{A}$, this difference was due to the significantly poorer performance of the schizophrenics when compared with the normal controls. For the letter B, the difference was accounted for by the significantly better performance of the manics than the schizophrenics. The group difference in performance on the semantic category was accounted for by the impaired performance of the schizophrenics in comparison with the normal subjects.

Of the two design fluency tests, only the "restricted" form significantly differentiated the groups. Post-hoc pairwise comparison showed this to be entirely due to the poorer performance of the schizophrenics compared with the normal subjects.

Both of the two tests of performance intelligence on the WAIS, the Object Assembly and Picture Arrangement tests, significantly differentiated the three groups. While the difference in the former was accounted for by the poorer scores of the schizophrenics compared with the normals, both of the patient groups scored significantly poorer than normals on the latter. On both of the tests of verbal intelligence that differentiated the groups (i.e. Digit Span backwards and Similarities), each of the two patient groups showed impaired performance in comparison with the normal controls.

In order to control for the potential confounding effects of age and previous level of education on the test results and to determine the relative importance of the tests at differentiating the groups, we performed a multiple regression analysis in which all the neuropsychological tests, age and years of education were forced into the equation. The results suggest that only four tests significantly differentiated the groups or showed a trend in that direction (Table 
TABLE II. Neuropsychological test performance of the groups

\begin{tabular}{|c|c|c|c|c|c|}
\hline & Normals & Schizophrenics & Manics & $\begin{array}{c}p \\
\text { (ANOVA) }\end{array}$ & $\begin{array}{c}\text { Tukey } \\
\text { HSD } \\
p<0.05\end{array}$ \\
\hline \multicolumn{6}{|l|}{ Logical Memory } \\
\hline Immediate recall & $8.0(2.77)$ & $7.1(2.69)$ & $6.7(2.36)$ & N.S. & - \\
\hline 5 min recall & $6.9(2.85)$ & $5.6(2.97)$ & $5.6(2.22)$ & 0.04 & - \\
\hline \multicolumn{6}{|l|}{ Verbal Fluency } \\
\hline Letter A & $9.6(4.36)$ & $6.3(3.16)$ & $7.8(3.57)$ & 0.0004 & $N>S$ \\
\hline Letter B & $3.3(1.77)$ & $2.4(2.25)$ & $3.7(2.41)$ & 0.03 & $M>S$ \\
\hline Animal naming & $12.0(3.80)$ & $10.0(4.14)$ & $10.3(3.07)$ & 0.016 & $N>S$ \\
\hline \multicolumn{6}{|l|}{ Design Fluency } \\
\hline No restriction & 5.4 (3.59) & 3.9 (3.01) & $4.2(2.74)$ & N.S. & - \\
\hline With restriction & $5.1(4.26)$ & $3.0(1.93)$ & $3.7(3.15)$ & 0.009 & $N>S$ \\
\hline \multicolumn{6}{|l|}{ WAIS Performance } \\
\hline Object Assembly & $26.6(9.80)$ & $20.1(9.10)$ & $21.4(11.10)$ & 0.004 & $\mathrm{~N}>\mathrm{S}$ \\
\hline Picture Arrangement & $14.3(6.39)$ & $10.4(5.12)$ & $11.0(5.26)$ & 0.003 & $N>S, N>M$ \\
\hline \multicolumn{6}{|l|}{ WAIS Verbal } \\
\hline Digit forward & $6.5(1.20)$ & $6.0(1.40)$ & $6.1(1.22)$ & N.S. & - \\
\hline Digit backward & $4.4(1.53)$ & $3.4(1.44)$ & $3.5(1.19)$ & 0.003 & $N>S, N>M$ \\
\hline Similarities & $12.0(4.29)$ & $9.6(4.67)$ & $9.6(4.31)$ & 0.01 & $\mathrm{~N}>\mathrm{S}, \mathrm{N}>\mathrm{M}$ \\
\hline
\end{tabular}

$\mathrm{N}$, normals; S, schizophrenics; M, manics.

TABLE III. Multiple regression analysis (forced entry)—variables making significant contribution to equation

\begin{tabular}{lccrrr}
\hline & \multicolumn{5}{c}{ Variable } \\
\cline { 2 - 6 } & $B$ & SEB & \multicolumn{1}{c}{$\beta$} & \multicolumn{1}{c}{$T$} & $p$ \\
\hline Design fluency & & & & & \\
$\quad$ No restriction & 0.094 & 0.048 & 0.344 & 1.965 & 0.054 \\
$\quad$ With restriction & 0.111 & 0.048 & -0.369 & -2.299 & 0.025 \\
$\quad \begin{array}{l}\text { Verbal fluency } \\
\quad \text { Letter A }\end{array}$ & -0.076 & 0.032 & -0.350 & -2.352 & 0.022 \\
Object Assembly & -0.024 & 0.011 & -0.313 & -2.206 & 0.031 \\
\hline
\end{tabular}

III). All the tests, except the Object Assembly, were tests of frontal lobe functioning.

Our results suggest that there was variation in the performance of the schizophrenics in the neuropsychological tests. We examined the basis for this variation by performing a correlational analysis between the test scores on the one hand and gender, duration of illness and symptomatology on the other. There were no significant correlations between the test scores and either gender or duration of illness. A factor analytical examination of the symptoms of the schizophrenic patients as rated on the SANS and the abridged BPRS produced three clusters of symptoms: a "negative" cluster consisting of affective flattening, anhedonia, avolition/apathy, and alogia accounted for $39.2 \%$ of the total variance; a "disorganization" cluster consisting of conceptual disorganization and attentional impairment accounted for $14.8 \%$ of the variance; and a "positive" cluster consisting of hallucinations, suspiciousness and unusual thought disorder accounted for $10.5 \%$ of the variance. The results of the correlational analysis between the tests and the three clusters are shown in Table IV. As can be seen, there was a consistent trend for the test scores to correlate more strongly with the "disorganization" syndrome than with the other two syndromes, with two of the correlation coefficients attaining statistical significance at the 0.01 level.

\section{DISCUSSION}

Using a battery of neuropsychological tests, we have shown that schizophrenics are different from normal subjects and from manics in respect of cognitive functioning that reflects the integrity of specific brain areas. We have studied a group of young Nigerian patients with relatively recent onset of illness, few

62 Behavioural Neurology . Vol 7 . 1994 
TABLE IV. Correlations of three syndromes of schizophrenia with neuropsychological test performance

\begin{tabular}{lrcr}
\hline & \multicolumn{3}{c}{ Syndromes } \\
\cline { 2 - 4 } Test & Negative & Disorganization & Positive \\
\hline Logical Memory & & & \\
$\quad$ Immediate recall & 0.04 & -0.20 & 0.09 \\
5 minute recall & 0.01 & -0.29 & 0.10 \\
Oral Word Association & & & \\
$\quad$ Letter A & 0.01 & $-0.42^{*}$ & -0.07 \\
$\quad$ Letter B & -0.11 & -0.33 & -0.27 \\
$\quad$ Animal names & -0.14 & -0.28 & -0.06 \\
Design Fluency & & & \\
$\quad$ Unrestricted & -0.05 & -0.20 & -0.10 \\
$\quad$ Restricted & -0.02 & -0.22 & -0.09 \\
WAIS Performance Tests & & & \\
$\quad$ Object Assembly & 0.30 & -0.30 & 0.02 \\
$\quad$ Picture Arrangement & -0.01 & -0.23 & -0.12 \\
WAIS Verbal Tests & & & \\
Forward digit span & -0.16 & -0.38 & 0.11 \\
$\quad$ Backward digit span & 0.07 & $-0.46^{\star}$ & 0.02 \\
$\quad$ Similarities & 0.10 & -0.45 & -0.22 \\
\hline * $p$ 0.01. & & &
\end{tabular}

hospitalizations and with no prolonged institutional care. The sample thus gave us the unique opportunity to address the questions relating to whether cognitive impairment in schizophrenia is a reflection of such impairment in all psychotic states, is evidence of impoverished institutional environment or of ageing, or whether patients with a putative better clinical outcome would evidence such impairment.

The validity and cerebral localization of the tests used in this study have been generally based on evidence derived from unilateral lesion studies. The Logical Memory Test is a test of immediate recall and recent semantic memory. The left frontal and temporal lobes, particularly the hippocampus, are the cerebral areas responsible for these functions (Geschwind, 1974; Luria, 1976). Verbal fluency tests generally assess frontal lobe functions. While fluency in response to letter category is associated with frontal impairment of either hemisphere (Benton, 1968; Miller, 1984), that in response to semantic category is associated with anterior or posterior left hemisphere lesions (Newcomb, 1969; Gruzelier et al., 1988). In this study, the existence of some functional independence between the two was supported by the low correlation between the total scores on the letter and semantic categories among the normal subjects $(r=0.29)$. Design fluency tests assess right frontal lobe functioning. This is confirmed in our study by the low correlations of these tests in normals with the semantic fluency test (unrestricted: $r=0.07$; re- stricted: $r=0.20$ ) and the higher correlations with the total of the letter fluency test (unrestricted: $r=$ 0.55 ; restricted: $r=0.26$ ). Poor performance in the Object Assembly and the Picture Arrangement subtests of the WAIS is associated with lesions of the right temporal lobe (McFie, 1960). Subjects with lesions in the right frontal lobe also show impairment on the latter (McFier and Thompson, 1972). Digit Span is a test of both attention and immediate memory and impaired performance reflects left parietal or temporoparietal dysfunction (Warrington and Shallice, 1969; Warrington et al., 1971). The similarities subtest is a test of abstraction which is subserved by the frontal lobe system (Flor-Henry et al., 1983)

There is controversy over the selection of appropriate control groups for the study of neuropsychological functioning in schizophrenia. Using patients with diagnoses other than schizophrenia assumes a degree of specificity of the impairments to schizophrenia, a view that is hardly justified by the body of present knowledge. Using normal controls matched for education and socioeconomic status can lead to erroneous conclusions. As pointed out by Saykin et al. (1991), schizophrenia could in itself impede education and produce a downward drift in socioeconomic status. It seems to us that using both normal and patient control groups, and studying patients with history of early onset, will attenuate the effects of these constraints. Nevertheless, one limitation of our study was our inability to more rigorously control the 
groups for premorbid functioning. It would have been desirable, for example, to control the groups for premorbid reading IQ. Unfortunately, such information is not routinely collected in the Nigerian educational system.

The overall results of our study support those of earlier investigations that show two levels of neuropsychological deficits in schizophrenia, one generalized and the other specific. Generalized dysfunction is implicit in the fact that schizophrenics performed significantly poorer than normal subjects in many functional areas. An earlier study of 16 monozygotic twin pairs discordant for schizophrenia and seven normal monozygotic twin pairs found that affected twins tended to perform worse than their unaffected counterparts on most of the items in a battery of neuropsychological tests (Goldberg et al., 1990). The authors showed that the deficits were related primarily to the clinical disease process and not to genetic or non-specific environmental factors by demonstrating no significant differences in the performance of discordant unaffected twins and the sample of seven pairs of normal twins. In the present study, the pattern of deficits in the manic patients would tend to suggest that this generalized dysfunction is, at least in part, a common effect of the psychotic state even though schizophrenics may be the most affected.

A second level of deficits in schizophrenia may be more circumscribed. In our sample, the evidence seems to implicate frontal lobe, possibly frontotemporal, dysfunction. The poorer performance of the schizophrenics than the controls in fluency tests is suggestive of frontal lobe dysfunction. However, since schizophrenics also had the poorest performance on tests such as Object Assembly and the Digit Span, a case for the broad involvement of frontotemporal structures can be made. While it can however be argued that the general drop in performance shown by subjects with schizophrenia could also explain the specific differences observed, particularly if the fluency tests are assumed to be more sensitive than the other tests, the result of our multivariate analysis suggests that a case can still be made for the presence of a specific frontal or frontotemporal deficit. Even so, our observation has to be interpreted with caution since we employed a relatively small number of tests designed to assess frontal lobe functioning. Indeed, the fluency tests are the components of our battery that can be regarded as traditional tests of frontal lobe functioning. Nevertheless, evidence is growing in the literature for either of such selective impairments. Goldberg et al. (1990) observed more severe deficits on tests of vigilance, memory and concept formation in their affected twins and suggested that impairment was more pronounced in the frontotemporal cortex. Even though Saykin and colleagues (1991) could not demonstrate selective impairment on tests related to frontal system function in their sample, they observed a pattern of dysfunction that was consistent with greater involvement of the temporohippocampal system. The hypofrontality hypothesis in schizophrenia has received support from studies using various neuropsychological tests, cerebral blood flow (Weinberger et al., 1986), various scanning techniques (Andreasen et al., 1986), and mapping of brain electrical activity (Morihisa and McAnulty, 1985).

The observation of a significantly poorer performance of the patient groups compared with the normal subjects may suggest that there was a common pattern of impaired effortful memory among the patients. However, and consistent with other reports (Gruzelier et al., 1988), we observed patterned deficits in the performance of the patients. Such an observation rules out the possibility that the impaired performance of the schizophrenics was due to poor motivation or to distractions from the test procedure as a result of hallucinatory experience. Indeed, as the result of correlations between neuropsychological test scores and clinical symptomatology shows, there was little association between the intensity of negative or positive symptoms and test performance. Rather, the syndrome complex characterized by conceptual disorganization and attentional impairment had a distinctly higher negative correlation with neuropsychological test scores. Even though others have suggested that attentional deficit may be central to the psychopathology of schizophrenia (Shakow, 1963), our findings suggest that such a deficit may characterize only a subgroup of patients with a form of the illness (Gur et al., 1991; Peralta et al., 1992). Thus, while our observation provides partial support for the view regarding schizophrenia as consisting of at least three syndromes (Liddle, 1987; Gur et al., 1991; Peralta et al., 1992), it also suggests that the group of patients that is particularly more likely to show cognitive impairment is that characterized by thought disorder and attentional disturbance.

\section{REFERENCES}

Andreasen NC (1983) The Scale for the Assessment of Negative Symptoms (SANS). The University of Iowa, Iowa City, IA.

Andreasen NC, Nasrallah HA, Dunn V, et al. (1986) Structural abnormalities in the frontal system in schizophrenia: a magnetic resonance imaging study. Archives of General Psychiatry, 43, 136-144. 
Benton AL (1968) Differential behavioural effects in frontal lobe disease. Neuropsychologia, 6, 53-60.

Benton AL and Hamsher K (1976) Multilingual Aphasia Examination. University of Iowa, Iowa City, IA.

Cooper J and Sartorius N (1977) Cultural and temporal variations in schizophrenia: a speculation on the importance of industrialization. British Journal of Psychiatry, 130, 50-55.

Flor-Henry P, Fromm-Auch D and Schopflocher D (1983) Neuropsychological dimensions in psychopathology. In: Laterality and Psychopathology. Elsevier BioMedical Press, Amsterdam.

Geschwind N (1974). The anatomical basis of hemispheric differentiation. In: Hemispheric Function in Human Brain (Eds SJ Dimond and JG Beaumont). Elek, London.

Gold JM and Hurt SW (1990) The effect of haloperidol on thought disorder and IQ in schizophrenia. Journal of Personality Assessment, 54, 390-400.

Goldberg TE, Weinberger DR, Berman KF, et al. (1987) Further evidence for dementia of the prefontal type in schizophrenia? A controlled study of teaching the Wisconsin Card Sorting Test. Archives of General Psychiatry, 44, 1008-1014.

Goldberg TE, Ragland JD, Torrey EF, et al. (1990) Neuropsychological assessment of monozygotic twins discordant for schizophrenia. Archives of General Psychiatry, 47, 1066-1072.

Gruzelier J, Seymour K, Wilson L, et al. (1988) Impairments on neuropsychologic tests of temporohippocampal and frontohippocampal functions and word fluency in remitting schizophrenia and affective disorders. Archives of General Psychiatry, 45, 623-626.

Gruzelier J, Wilson L, Peters E, et al. (1989) Recognition memory for words versus faces in syndromes of schizophrenia. Schizophrenia Research, 2, 64.

Gur RE (1978) Left hemisphere dysfunction and left hemisphere overactivation in schizophrenia. Journal of Abnormal Psychology, 87, 226-380.

Gur RE, Mozley PD, Resnick SM, et al. (1991) Relations among clinical scales in schizophrenia. American Journal of Psychiatry, 148, 472-478.

Gureje O (1989) Correlates of positive and negative schizophrenic syndromes in Nigerian patients. British Journal of Psychiatry, 155, 628-632.

Jones-Gotman M and Milner B (1977) Design fluency: the invention of nonsense drawings after focal cortical lesions. Neuropsychologia, 15, 653-674.

Keefe RSE, Mohs RC, Losonczy MF et al. Characteristics of very poor outcome schizophrenia. American Journal of Psychiatry, 144, 889-895.

Kolb B and Whishaw IQ (1983) Performance of schizophrenic patients on test sensitive to the left or right frontal temporal, and parietal function in neurologic patients. Journal of Nervous and Mental Disease, 171, 435-443.

Liddle PF (1987) Schizophrenic syndromes, cognitive performance and neurological dysfunction. Psychological Medicine, 16, 49-57.

Luria AR (1976) The Neuropsychology of Memory. John Wiley, New York.

McFie J (1960) Psychological testing in clinical neurology. Journal of Nervous and Mental Disease, 131, 383393.
McFier J and Thompson JA (1972) Picture arrangement: a measure of frontal lobefunction? British Journal of Psychiatry, 121, 547-552.

Mesulam M-M (1990) Schizophrenia and the brain. New England Journal of Medicine, 322, 842-845.

Miller E (1984) Verbal fluency as a function of a measure of verbal intelligence and in relation to different types of cerebral pathology. British Journal of Clinical Psychology, 23, 53-57.

Morihisa JM and McAnulty GE (1985) Structure and function: Brain electrical activity mapping and computed tomography in schizophrenia. Biological Psychiatry, 20, 3-19.

Neale JM, Winters KC and Weintraub S (1984) Information processing deficits in children at high risk for schizophrenia. In: Children at Risk for Schizophrenia (Eds NE Watt, EJ Anthony, LC Wynne and JE Rolf), pp. 264278. Cambridge University Press, New York.

Newcomb F (1969) Missile Wounds of the Brain, Oxford University Press, New York.

Overall JE and Gorham DR (1962) Brief psychiatric rating scale. Psychological Reports, 10, 799-812.

Peralta V, de Leon J and Cuesta MJ (1992) Are there more than two syndromes in schizophrenia? A critique of the positive-negative dichotomy. British Journal of Psychiatry, 161, 335-343.

Robins LN, Wing J, Wittchen HU, et al. (1988) The Composite International Diagnostic Interview. Archives of General Psychiatry, 45, 1069-1077.

Sartorius N, Jablensky A, Korten A, et al. (1986) Early manifestations and first-contact incidence of schizophrenia in different cultures. Psychological Medicine, 16, 909-928.

Saykin AJ, Gur RC, Gur RE et al. (1991) Neuropsychological function in schizophrenia: selective impairment in memory and learning. Archives of General Psychiatry, 48, 618-624.

Shakow D (1963) Psychological deficit in schizophrenia. Behavioral Science, 8, 275-305.

Spitzer RL, Endicott J, Fleiss JL et al. (1970) The Psychiatric Status Schedule: a technique for evaluating psychopathology and impairment in role functioning. Archives of General Psychiatry, 23, 41-55.

Spitzer RL, Endicott J and Robins E (1978) Research Diagnostic Criteria: rationale and reliability. Archives of General Psychiatry, 35, 773-782.

Taylor MA and Abrams R (1984) Cognitive impairment in schizophrenia. American Journal of Psychiatry, 141, 196201.

Tsuang MT, Lyons MJ and Faraone SV (1990) Heterogeneity of schizophrenia: conceptual models and analytic strategies. British Journal of Psychiatry, 156, 17-26.

Wallace CJ (1984) Community and interpersonal functioning in the course of schizophrenic disorders. Schizophrenia Bulletin, 10, 233-257.

Warrington EK and Shallice T (1969) The selective impairment of auditory verbal short-term memory. Brain, 92, 885-896.

Warrington EK, Logue V and Pratt RTC (1971) The anatomical localization of selective impairment of auditory short-term memory. Neuropsychologia, 9, 377-387.

Wechsler D (1945) A standardized memory scale for clinical use. Journal of Psychology, 19, 87-95.

Wechsler D (1955) Wechsler Adult Intelligence Scale Mannual. The Psychological Corp., New York. 
O. GUREJE ET AL

Weinberger DR, Berman KF and Zec RF (1986) Physiologic dysfunction of dosolateral prefontal cortex in schizophrenia, 1: regional cerebral blood flow evidence. Archives of General Psychiatry, 43, 114-125.

Withers E and Hinton J (1971) Three forms of the clinical tests of the sensorium and their reliability. British Journal of Psychiatry, 119, 1-8.

(Received January 1994; accepted as revised 16 June 1994)

66 Behavioural Neurology . Vol 7 . 1994 


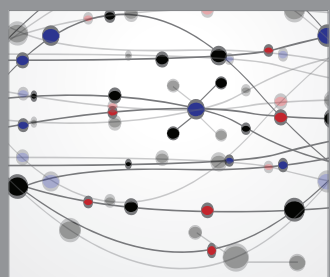

The Scientific World Journal
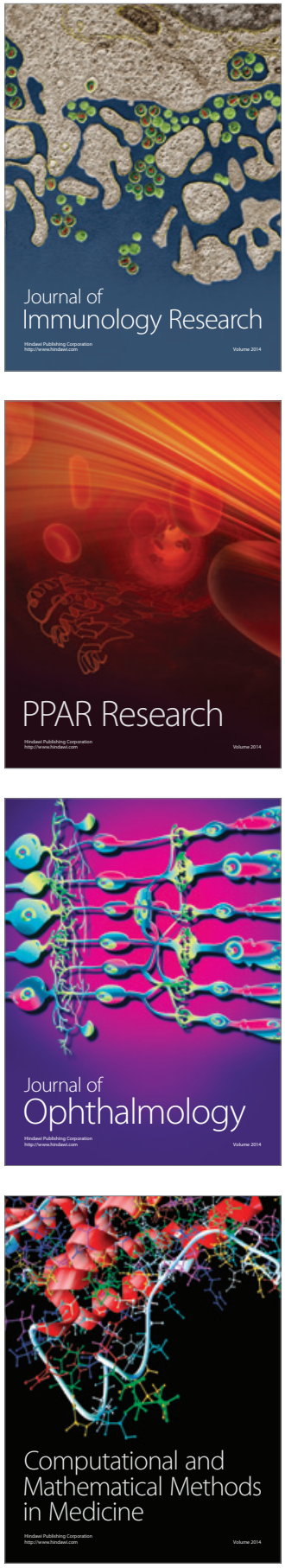

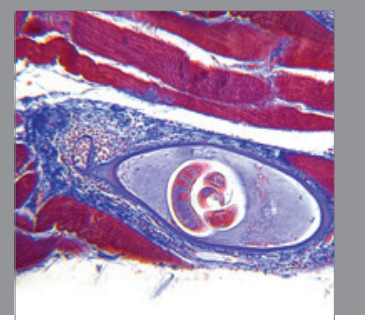

Gastroenterology

Research and Practice
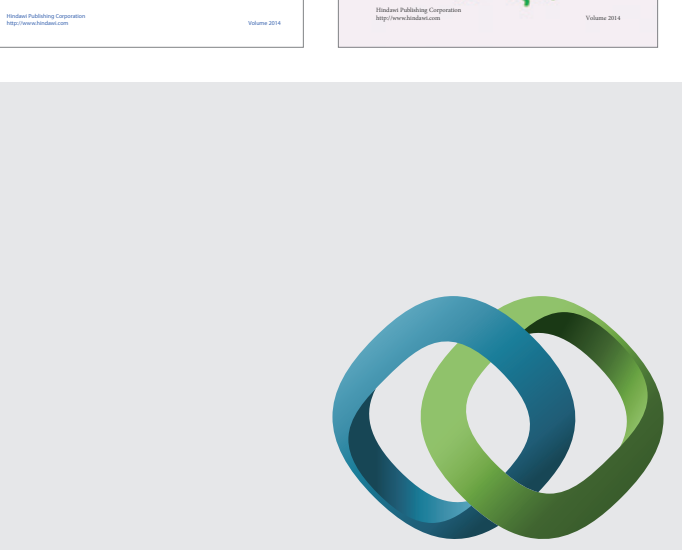

\section{Hindawi}

Submit your manuscripts at

http://www.hindawi.com
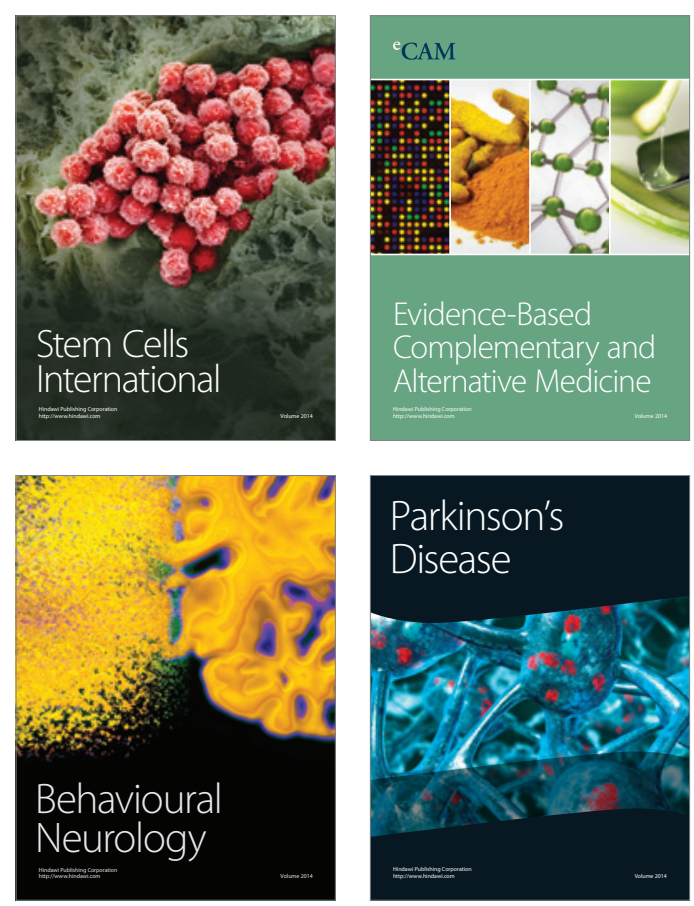

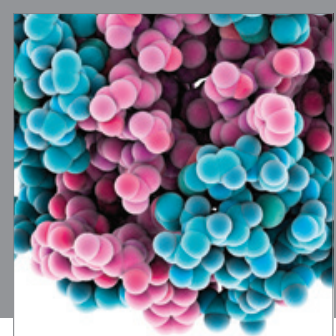

Journal of
Diabetes Research

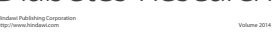

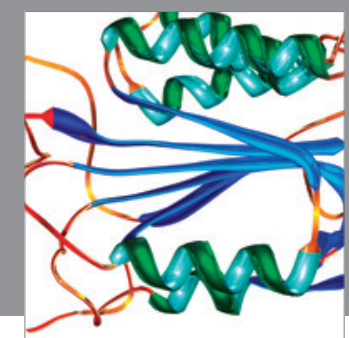

Disease Markers
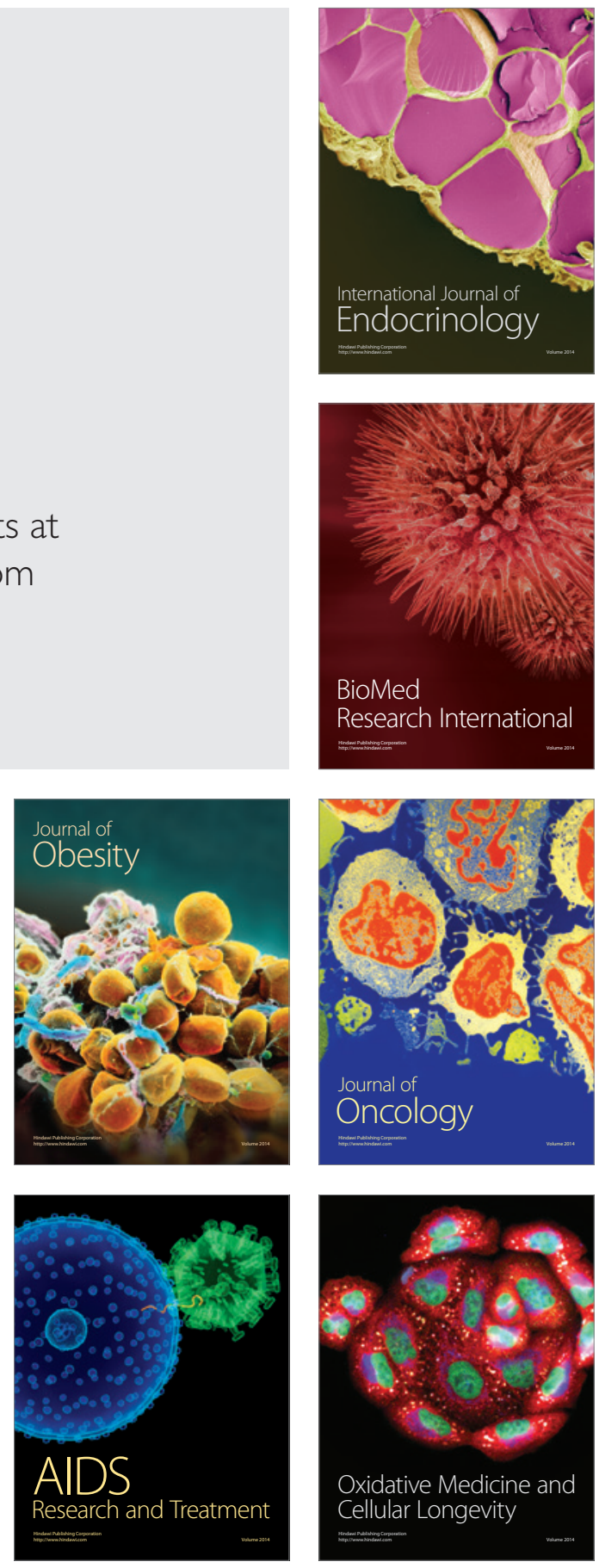